\title{
A EDUCAÇÃO CONTEMPORÂNEA: UM (DES) CASO PENSADO SOBRE INCLUSÃO
}

\section{CONTEMPORARY EDUCATION: A NEGLIGENCE THOUGHT ABOUT INCLUSION}

\author{
Daniel Novaes ${ }^{1}$ \\ Carlos Roberto da Silveira ${ }^{2}$ \\ Marcia Aparecida Amador Mascia ${ }^{3}$
}

\begin{abstract}
Resumo: Este artigo tem por objetivo explicitar algumas contribuições da perspectiva históricocultural na reflexão acerca da inclusão escolar de crianças com transtorno do espectro autista. A educação e a escolarização na contemporaneidade, como fruto do atual modelo político econômico neoliberal, culminam em um esvaziamento do espaço público, das relações interpessoais e empobrece as experiências do contato humano com a natureza (humana ou natural). Logo, o não pertencimento se faz presente. Transforma-se a natureza a ponto de os seres humanos não se reconhecerem como parte dela. A cada passo dado, um sucesso, um momento de fama, numa busca narcísica que não promove a humanidade. Como metodologia, a abordagem narrativa serve como fio para tecer a trama deste texto. Assim, parte-se de uma foto tirada em uma viagem de trem de Várzea Paulista à São Paulo. O deslocamento provocado é a busca em contrapor o que se tem por inclusão no contexto escolar e qual inclusão realmente é necessária para haver uma 'perspectiva da educação inclusiva', à mercê das seguintes questões: o que significa inclusão? Qual o sentido de se dizer 'perspectiva da educação inclusiva'? Quais são os sujeitos 'incluídos' na política de inclusão escolar? Por fim, indaga-se a respeito de qual a finalidade do ensino para essas pessoas sujeitadas por um diagnóstico clínico?
\end{abstract}

Palavras-chave: Teoria Histórico-Cultural; educação inclusiva; atividades de ensinoaprendizagem.

\begin{abstract}
This article aims at explaining some contributions from the historical-cultural perspective in the reflection on the school inclusion of children with autistic spectrum disorder. Education and schooling in contemporary times, as the fruit of the current neoliberal political economic model, culminate in an emptiness of public space, of interpersonal relationships and impoverishes the experiences of human contact with nature (human or natural). Therefore, non belonging is present. Nature is transformed to the point where human beings do not recognize themselves as part of it. With each step taken, a success, a moment of fame, in a narcissistic search that does not promote humanity. As a methodology, the narrative approach serves as a thread to weave the plot of this text. Thus, it begins with a photo taken on a train trip from Várzea Paulista to São Paulo. The displacement provoked is the search to counterbalance what is meant by inclusion in the school context and what inclusion is really necessary to have an 'inclusive education perspective', at the mercy of the following questions: what does inclusion mean? What is the point of saying 'inclusive education perspective'? What are the 'included' subjects in school inclusion policy? Finally, what is the purpose of education for those subject to a clinical diagnosis?
\end{abstract}

Keywords: Cultural history theory; inclusive education; activity learning.

\footnotetext{
${ }^{1}$ Universidade São Francisco, Itatiba, SP, Brasil.

${ }^{2}$ Universidade São Francisco, Itatiba, SP, Brasil.

${ }^{3}$ Universidade São Francisco, Itatiba, SP, Brasil.
} 


\section{Introdução}

No Brasil, a aposta educacional em "softwares" tem sido, hegemonicamente, a solução para os problemas que os professores apresentam como o não saber fazer ou a insegurança em dar aula para crianças com transtorno do espectro autista. Embora a tecnologia se mostre aliada ao fazer docente, ela não é ingênua e vem do movimento de esvaziamento das relações interpessoais, fruto do sistema político e econômico neoliberal. $\mathrm{O}$ gesto do outro, o olhar e o toque perdem espaço para o clique do mouse e a tela do computador. A informatização da educação, fragiliza a educação inclusiva.

Refletir a respeito da educação inclusiva na contemporaneidade, sobretudo, no processo de escolarização de pessoas diagnosticadas com transtorno do espectro autista, só, o ato de refletir, é uma resistência, visto que a informatização e a mecanicidade dos métodos educacionais para esse público precariza a interrelação com o outro. Além disso, no sistema político e econômico neoliberal, o tempo fabril da produtividade e do lucro tem sido introjetado na escola e nas relações de ensino. A atividade humana não consciente é utilizada como moeda de barganha em detrimento do tal produtivismo (BIANCHETTI; VALE, 2011). Vale pontuar que não estou tecendo uma crítica ao sistema político-econômico, neste ponto, situo o leitor a respeito de como as relações de trabalho acontecem no ano de 2019.

Com vista ao exposto, entendo que o momento de parar e refletir sobre si na relação com a pessoa com transtorno do espectro autismo que, em muitas situações é sujeitada a sobras de trabalhos e atividades escolares, e, por vezes, designada a tarefas sem funções, é por si só, uma resistência - da esfera do tangível, do necessário, do que mobiliza e desloca de como diz Pino (2000) da esfera do humano.

O dito reitera a legitimidade das questões deste estudo. O que significa inclusão escolar? Qual o sentido de se dizer perspectiva da educação inclusiva? Quais são os sujeitos incluídos na política de inclusão escolar? Qual a finalidade do ensino para essas pessoas sujeitadas por um diagnóstico clínico? Trago essas questões como marcas da minha intencionalidade enquanto autor deste texto sem a pretensão de respondê-las. Minha atividade humana de escritor e pesquisador, marcada pela ideologia de um pensamento intencional e consciente é legitimada pela necessidade, vontade de ou curiosidade. Nos rastros desses questionamentos o investigador busca refletir e transformar, o conhecimento e a si mesmo, como em uma ciência forense - busca das pistas e dos indícios, não do crime, mas dos mistérios que circundam o desenvolvimento do humano.

\section{Considerações metodológicas}

Com o intuito de explicitar algumas contribuições da perspectiva histórico-cultural, na reflexão acerca da inclusão escolar de crianças com transtorno do espectro autista, utilizei como base teórico-metodológica as considerações de Vigotski (1997) e Davidov (1988) acerca do desenvolvimento humano. Vigotski e Davidov dialogam a respeito das leis que regem o desenvolvimento humano. Os autores se fundamentam no materialismo histórico e dialético e compreendem que o homem nasce como ser biológico, mas desenvolve-se culturalmente. À luz desses dizeres, uma foto, uma lembrança e um gesto são tocados por nós e nos tocam de modo

\footnotetext{
${ }^{4}$ O ministério da ciência recebe "startup" brasileira vencedora de prêmio internacional. O "software" em questão é um aplicativo utilizado em 149 países. Além da invasão de privacidade, pois “[...] no jogo também existem algoritmos de leitura comportamental que coletam dados da criança, como suas reações durante o jogo e sua evolução em determinadas áreas [...]" (BRASIL, 2021), o aplicativo restringe a criança com dificuldade de relacionamento interpessoal à máquina. O ensino que apoiamos tem, no meio escolar, social e cultural, a via para transformar o que está em defasagem no desenvolvimento biopsíquicossocial.
} 
consciente e intencional - um conteúdo teórico que mobiliza, desloca o agir do sujeito no mundo, o constitui (DAVIDOV, 1999).

Então, como explicar metodologicamente o processo de (re)memorar e questionar a realidade em que estamos inseridos?

A partir do diálogo entre a teoria histórico-cultural, a abordagem narrativa e a escrita de si mesmo - diálogos que promovam a convergência entre a teoria de Vigotski e a abordagem narrativa, que pode acontecer via escrita narrativa. Vigotski (2009) considera que o narrar é uma atividade humana consciente e constitutivo da espécie. Em seu estudo sobre a arte, o autor exemplifica por meio da história da jovem colegial Ólia, como os sentidos sobre si são construídos na interrelação com o outro. Já a escrita de si mesmo é interrelacionada com a abordagem narrativa, "[...]visto que experiência e narrativa utilizadas como artefatos políticos de pesquisa dão passagem a um caráter radicalmente singular e impessoal: um pesquisador e um mundo aptos a serem criados e a serem destruídos - mais do que serem declarados ou descobertos" (MIZOGUCHI, 2015, p. 207). Nacarato, Passos e Silva (2014) partem do contexto da educação matemática para elucidarem que essa categoria de pesquisa possibilita o movimento da subjetividade dos envolvidos no processo de produção da trama da pesquisa.

Muitas pesquisas utilizam-se de entrevistas, memórias, diários etc. como modos de produção de dados. O que pode ocorrer são variações nos modos de apresentação dessa produção. Esses instrumentos geralmente se apresentam na forma de texto escrito. Por exemplo, as entrevistas podem ser textualizadas ou não; mesmo em caso de textualização, pode-se apenas retirar as marcas da oralidade das falas dos depoentes, mantendo as intervenções do pesquisador no ato da entrevista (as perguntas), ou elas podem ser reescritas, dando-lhes a forma de um texto, com uma história de trajetória organizada no espaço-tempo dos acontecimentos (NACARATO; PASSOS; SILVA, 2014, p. 714).

Abordagem narrativa e foucaultiana dialogam entre si visto que não buscam não desvelar ou encontrar a verdade, mas "[...] produzir o mundo de modo singular e sempre inacabado [...]" (MIZOGUCHI, 2015, p. 199). Os movimentos de pesquisa e a trajetória da história são construídos em movimento dialético, com idas e vindas. Mas sua poeticidade não retiram o caráter da produção científica, pelo contrário, possibilita, como afirma Davidov (1999), que o homem seja um ser transformador e criador.

\section{Uma lembrança: do fio à trama}

A narrativa constitui o homem, possibilita o entendimento do discurso intersubjetivo e, compreendê-lo é encontrar as pistas e os indícios do processo em curso. No dia da foto fui convidado por minha irmã para ir da cidade de Várzea Paulista à São Paulo escolher seu violoncelo. Fazia tempo que eu não andava de trem e, ao entrar, o movimento dos vendedores me chamou a atenção, pois desde minha última viagem pela estrada férrea, o número triplicou.

Entre as estações, os ambulantes trocavam de vagão. Por conta disso, a mercadoria se diversificou durante a viagem. Eles vendiam: água, cerveja, bolacha recheada, barras de cereal, fone de ouvido, relógio e havia uma senhora doente, suas bolhas em seu corpo esguio me fez pensar na vida e em minhas relações, ela tinha câncer e pedia alimento. Às margens do trilho, a paisagem externa se completava ao movimento interno dos ambulantes, fui mobilizado por essas situações e comecei a deslocar-me. Meu corpo ainda se mantinha sentado, mas os pensamentos caminharam pela extensão do território brasileiro e, se de um lado eu encontrava meus sonhos para além das minhas necessidades, de outro me deparava com a situação da fome, miséria e pobreza. 


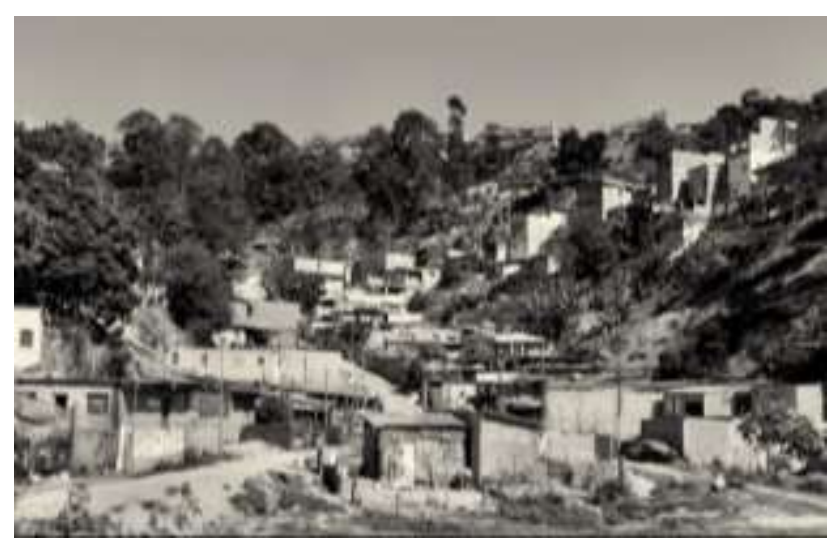

Figura1 - Caminho para São Paulo Fonte: Daniel Novaes, 2017.

Por conta disso, comecei a refletir a respeito das situações em que nossas escolas se encontram, sobretudo a respeito de como o sistema político implica no fazer do professor e nas metodologias de ensino. Por isso, entende-se que, se hegemonicamente os "softwares" e as atividades mecânicas para alunos com espectro autista se mostram uma saída educacional de sucesso, por outro, há uma inquietação de que tais recursos didáticos não cheguem para todas as pessoas.

Comecei, então, a refletir a respeito de que a educação inclusiva, não podia, naquele momento, ser pensada fora do contexto da fotografia. Conceber o ser humano, aqui, é congregar à sua esfera de humano, suas relações inter e intrassubjetivas. Mas de qual inclusão falamos? Veiga-Neto (2001) pontua que a ideia de inclusão no contexto escolar está posta no sentido das vantagens e desvantagens de agrupar na sala de aula, alunos deficientes e não deficientes, porém, não se restringe a isso. $\mathrm{O}$ autor esclarece que em sala de aula, o acolhimento do deficiente possibilita tensionar o conceito de normalidade. Então, nesse caso, os planos de aula não seriam para o deficiente ou para o sem deficiência, mas para todos, com objetivos que consideram o aluno como ser que se desenvolve em um contexto sócio-histórico-cultural.

\subsection{O pensar de Davidov sobre o humano: a educação contemporânea}

De repente, uma quebra no texto. Da luz às trevas. Um tropeção na formalidade que me tira da tristeza e leva à alegria. Feliz estou. Pois como Sócrates, só sei de que nada sei.

Daniel Novaes

Pensar no homem contemporâneo, sobretudo na inclusão, arraigados em Davidov (1999) é movimentar-se e acreditar na transformação criativa de todo um modo de vida. $\mathrm{O}$ autor pontua que para que aconteça a transformação, a educação é primordial. O modo no qual a escola está organizada não faz sentido para o aluno. A perspectiva da educação inclusiva é perpassada de avanços e retrocessos. Neves et. al. (2018) consideram que a legislação de educação especial/inclusiva brasileira, ao agrupar diversos grupos sociais, extravasam as incumbências da escola. Esse extravasar é necessário, não se pode conceber uma educação estruturada e informatizada para alunos com transtorno do espectro autista, desconsiderado o seu contexto de habitação.

Para a pessoa com deficiência "[...] é preciso efetivar medidas e ações que contemplem a inclusão efetiva de crianças, jovens e adultos com deficiência, transtornos globais do desenvolvimento e altas habilidades ou superdotação [...]" (NEVES et. al. 2018, p. 200). A educação inclusiva precisa fazer sentido para o aluno com deficiência, é necessário que o pedagogo intencione o ensino, tendo 
em vista "[...] a organização do aprendizado dos alunos dos conhecimentos e habilidades sob a forma de atividade de estudo" (DAVIDOV, 1999, p. 1). Enquanto conceito filosófico-pedagógico, a atividade é o processo de transformação criativa numa dada realidade. A realidade, no que lhe concerne e, com base na perspectiva histórico-cultural, é datada e culturalmente situada, o que possibilita o movimento de desvelar a singularidade do tempo atual.

A educação contemporânea e as questões que tocam na perspectiva da educação inclusiva são pertinentes às tessituras de Davidov (1999) no que diz respeito, também, às particularidades do conceito da atividade. Com seu caráter de objeto lumiado ou não "[...] todos os seus componentes têm um ou outro conteúdo de objeto, e ela própria está obrigatoriamente dirigida para a edificação criativa de um produto material ou espiritual determinado [...]" (DAVIDOV, 1999, p. 1). Mas não é esse tipo de educação que o atual sistema político-econômico requisita dos sistemas educacionais, e isso envolve a educação inclusiva, a demanda é pelo esvaziamento das políticas públicas que garantem o acesso ao conhecimento cultural, a priorização é do coletivo. Nesse caso, o coletivo tem uma cara só, a do sistema político-econômico atual, e o que se defende neste estudo é um coletivo composto por muitas faces singulares.

É nesse ponto que a abordagem narrativa entra em cena. Narrativas de vida. Um nome singular para um método minucioso de acolhida à voz do outro. A possibilidade de vir a ser dos sujeitos mobiliza um movimento nem sempre percebido no ato da fala ou da escrita, traz à luz um modo de formação docente e constituição humana. O subjetivo que vem à tona por meio da pesquisa narrativa, é (re)construído histórica e culturalmente quando se localiza os fragmentos que marcam as vozes dos sujeitos e seus locais de vida e de trabalho. Ademais, é por meio do ato de (re)memorar que a narrativa vai se construindo, do plano interpsíquico para o intrapsíquico.

Trouxe uma foto, fruto de um certo esforço para (re)memorar o que me deslocou na paisagem. O que quero com ela? Provocar a pensar no que de fato chamamos de inclusão na escola, problematizando, o conceito de educação e escolarização. De que modo? A reflexão é pautada na perspectiva histórico-cultural, e que, para mim, é fruto de um ensino escolarizado. Nas palavras de Davidov

O pensamento teórico não surge e nem se desenvolve na vida cotidiana das pessoas, ele se desenvolve somente em uma tal instrução, cujos programas se baseiam na compreensão dialética do pensamento. É exatamente este ensino que tem o caráter desenvolvimental (desenvolvente). Portanto a elaboração e a realização de tais programas são extremamente necessárias para a educação russa, se ele no processo de reforma tiver como meta assegurar o desenvolvimento autêntico das forças intelectuais dos jovens (DAVIDOV, 1999, p. 7).

Então, se olho a paisagem e o movimento dos vendedores e me questiono, esse questionamento e olhar, trazem as marcas da minha intencionalidade. Fui afetado por um conhecimento teórico e esse conhecimento teórico se movimentou com a minha subjetividade, a ponto de não saber mais, quem sou eu, quem é outro. Para explicar trago uma citação de Davidov (1999) a respeito da construção consciente do conhecimento.

A criança assimila um certo material sob a forma de Atividade de estudo somente quando ela tem uma necessidade e motivação interior para tal assimilação. Ademais, isto está relacionado com uma transformação do material assimilado e desta forma com a obtenção de um novo produto espiritual, ou seja, de conhecimento deste material. Sem isto não há uma plena atividade humana (DAVIDOV, 1999, p. 2). 
Conhecimento esse que transforma e cria relações humanas e humanizadas e, transforma e cria o próprio ser humano.

\section{Considerações finais}

Uma colcha de retalhos para um morador de rua é o cordão de ouro que enfeita o bancário.

Daniel Novaes

Tivemos como objetivo explicitar algumas contribuições da perspectiva histórico-cultural na reflexão acerca da inclusão escolar de crianças com transtorno do espectro autista. Iniciamos essa trama situando o leitor de qual época falamos para pensar sobre inclusão e, qual o sentido que esse assunto traz ao discurso. Sentido esse, de resistência. Em seguida, trouxemos uma foto e um texto para compor a foto. O trazido foi intencional e com o propósito de provocar. Quem incluímos em nossas escolas? Incluímos? Em seguida, partimos para as seguintes questões: o que significa inclusão? Qual o sentido de se dizer, 'perspectiva da educação inclusiva? Quais são os sujeitos 'incluídos' na política de inclusão escolar? E por fim, qual a finalidade do ensino para essas pessoas sujeitadas por um laudo?

O objetivo desta trama não é responder a tais questões, mas quem sabe, entender a problemática, e compreender que elas não são frutos da mágica das gavetas. Os deslocamentos fazem parte do processo intencional da pesquisa. Assim como a ciência forense, responder o mistério.

Quando me coloco no papel do outro e busco compreender o que seus gestos estão interpretando, passo a perceber uma sociedade onde todos estão incluídos nela, e não à margem, o camelô tem o seu trabalho, sua necessidade, o médico tem o seu trabalho, a sua necessidade, a pessoa tida como deficiente tem o seu trabalho, a sua necessidade e assim por diante. Nesse sentido, a reflexão inicial acerca do ensino mecanizado e informatizado para alunos com transtorno do espectro autista não faz sentido, por desconsiderar, sobretudo, a narrativa de cada pessoa, sua história e a necessidade que ela precisa suprir por meio da educação.

Ao considerar que todos os seres humanos estão em constante processo de desenvolvimento, devido à necessidade (desde os primórdios quando faz o fogo até a comunicação na e pela linguagem), ao sanar uma necessidade, Marx (1979) diz que outras irão surgir, por isso o desenvolvimento do ser humano é sempre um processo. E não cabe a ninguém se dizer normal, ou classificar o outro como anormal, precisamos extrapolar as concepções hegemônicas que limitam o homem à sua mera possibilidade genética, precisamos conceber um ensino para além das concepções mecanizadas na qual, a interrelação com o outro se dá "softwares" educacionais.

Pensamos na educação e na escolarização de pessoas com transtorno do espectro autista como lugar onde todos estão em suas singularidades, étnicas, sociais, culturais, físicas. Então não cabe falar em inclusão e vincular a essa palavra a construção social do que é ser deficiente, pois, assim como o vendedor e qualquer outra pessoa. É crucial a compreensão de que somos todos especiais e sem fama. Somos além de nossos corpos, imaginadores, atores, criadores e transformadores, pois o morador de rua, à margem da informatização, transforma a paisagem com o seu papelão, seria o seu trabalho de pedinte para a sua necessidade, outra coisa além de trabalho, ou estamos cegos por construções sociais de determinados trabalhos e do que é ser digno?

Consideramos com este artigo a fundamental necessidade de se repensar conceitos como: educação, inclusão e deficiência, considerando a singularidade do ser humano e a atividade de (re)criação da realidade. Conceber o homem como singular, possibilitará a compreensão da necessidade de um ensino que valorize o olhar, os gestos, o toque e o afeto. Em suma, professores e alunos precisam de uma relação para além da tela do computador, real. 


\section{Referências}

BIANCHETTI, Lucídio; VALLE, Ione Ribeiro. Produtivismo acadêmico e decorrências às condições de vida/trabalho de pesquisadores brasileiros e europeus. In: SIMPÓSIO BRASILEIRO DE POLÍTICA E ADMINISTRAÇÃO DA EDUCAÇÃO, 25., 2011, São Paulo. Anais... São Paulo, SP, 2011. Disponível em: https://anpae.org.br/simposio2011/cdrom2011/PDFs/trabalhosCompletos/comunicacoesRelatos/0301.pdf.

Acesso em: 28 de janeiro de 2021.

BRASIL. Governo Federal. Ministério da Ciência, Tecnologia e Inovações. Ministro recebe startup brasileira vencedora de prêmio internacional com App para pessoas com autismo. Disponível em: https://www.gov.br/mcti/pt-br/acompanhe-o-mcti/noticias/2021/01/softwareterapeutico-que-ajuda-no-tratamento-do-autismo-e-apresentado-no-mcti. Acesso em: 28 de janeiro de 2021.

DAVIDOV, V. V. Problemas do Ensino Desenvolvimental: A Experiência da Pesquisa Teórica e Experimental na Psicologia. Tradução de José Carlos Libâneo e Raquel A. M. da Madeira Freitas. 1988. Disponível em: http://professor.pucgoias.edu.br/SiteDocente/admin/arquivosUpload/5146/material/DAVYDOV\%20TRADU \%C3\%87\%C3\%830\%20PROBLEMS\%200F\%20DEVELOPMENTAL\%20TEACHING\%20(Livro).do c. Acesso em: 22 de março de 2018.

DAVIDOV, Vasily Vasilovich. O que é a Atividade de estudo. Revista Escola inicial, n. 7, 1999. Tradução de José Carlos Libâneo, Raquel A. Marra da M. Freitas, Beatriz Aparecida Zanatta. Disponível em: http://professor.pucgoias.edu.br/SiteDocente/admin/arquivos Upload/5146/material/Davidov\%200\%20que\%20\%C3\%A9\%20atividade\%20de\%20estudo.d oc. Acesso em: 21 de novembro de 2018.

MARX, Karl. Excertos da Ideologia Alemã. In: FROMM, Erich. Conceito Marxista de Homem. Rio de Janeiro: Editora Zahar, 1979.

MIZOGUCHI, Danichi Hausen. Experiência e narrativa: artefatos políticos de pesquisa. ECOS: Estudos Contemporâneos da Subjetividade, Universidade Federal Fluminense, Campos dos Goytacazes, RJ, v. 5, n. 2, 2015. Disponível em: http://www.periodicoshumanas.uff.br/ecos/article/view/1352. Acesso em: 29 de janeiro de 2021

NACARATO, Adair Mendes. PASSOS, Cármen Lucia Brancaglion. SILVA, Heloisa da. Narrativas na pesquisa em Educação Matemática: caleidoscópio teórico e metodológico. Bolema, Rio Claro (SP), v. 28, n. 49, p. 701-716, ago. 2014. Disponível em: http://www.scielo.br/scielo.php?script=sci_arttext\&pid=S0103-636X2014000200701. Acesso em: 22 de novembro de 2018

NEVES, João Paulo Santos; AIRES, Laís Simões de Moura; FERNANDES, Fernanda de Sousa; COSTA, Bruna de Araújo. A educação especial brasileira: avanços e retrocessos na educação de alunos com necessidades educacionais especiais à luz da legislação brasileira. Cadernos $R C C$, v. 5, n. 1, 2018. Disponível em: http://www.periodicos.se.df.gov.br/index.php/comcenso/article/view/355. Acesso em: 28 de janeiro de 2021. 
PINO SIGARDO, Angel. O social e o cultural na obra de Lev S. Vigotski. Educação e Sociedade, número especial, 2000. Disponível em: http://www.scielo.br/scielo.php?pid=S010173302000000200003\&script=sci_abstract\&tlng=pt. Acesso em: 21 de novembro de 2018.

VEIGA-NETO, Alfredo. Incluir para excluir. In: LARROSA, Jorge; SKLIAR, Carlos. Habitantes de Babel. Belo Horizonte: Autêntica, 2001.

VYGOTSKY, Lev Semyonovich. La colectividad como factor de desarrollo del niño deficiente. In: VYGOTSKY, Lev Semyonovich. Obras escogidas V: Fundamentos de defectología. Madri: Visor, 1997. p. 213-234.

\section{Sobre os autores}

Daniel Novaes. Graduado em Pedagogia (Universidade Paulista), tem especialização em Educação Especial com ênfase em Deficiência Intelectual (Centro Universitário Padre Anchieta), é Mestre em Educação (Universidade São Francisco), e Doutorando em Educação (Universidade São Francisco). Tem experiência na área de Educação e Educação especial. Bolsista de Doutorado da Coordenação e Aperfeiçoamento de Pessoal de Nível Superior.

E-mail: msdanielnovaes13@gmail.com.

Carlos Roberto da Silveira. Graduado em Administração de Empresas (Faculdade de Administração e informática de Santa Rita do Sapucaí), tem Mestrado em Filosofia (Pontifícia Universidade Católica de Campinas) e Doutorado em Filosofia (Pontifícia Universidade Católica de São Paulo). É professor/pesquisador Stricto Sensu da Universidade São Francisco. Tem experiência na área de Educação, Filosofia da Educação, Teorias Críticas LatinoAmericanas, Epistemologias do Sul e Personalismo, o que envolve questões sobre ética, bioética, constituição do sujeito contemporâneo, decolonialidade, tecnologias, dentre outros.

E-mail: carlosilveir@yahoo.com.br.

Márcia Aparecida Amador Mascia. Graduada em Letras (Universidade Estadual Paulista), tem Mestrado em Linguística e Língua Portuguesa (Universidade Estadual Paulista) e Doutorado em Linguística Aplicada (Universidade de Campinas). Tem experiência na área de Educação e Linguística Aplicada, com pesquisa nos seguintes temas: ensino-aprendizagem de línguas, sujeito e discurso, discurso político educacional, avaliações externas. Bolsista PQ-CNPq.

E-mail: marciaaam@uol.com.br. 